\title{
Is surrogacy morally acceptable in Hong Kong?
}

\author{
LUK Hi Kwan Bronya \\ School of Nursing, Tung Wah College, \\ Tung Wah College, Kowloon, Hong Kong \\ Email: hkluk@twc.edu.hk
}

\author{
FU Chui Yuk Idy \\ School of Nursing, Tung Wah College, \\ Tung Wah College, Kowloon, Hong Kong \\ Email: idyfu@twc.edu.hk
}

\begin{abstract}
Surrogacy is always a controversial topic in the world, especially when it is with payment. In this article, the issues about the surrogacy and its risks the women's health, treating women as a commodity, constitutes babies-selling, changes the traditional family structure and values, degrades women productive dignity and exploits women from lower social stratum have been discussed. In Hong Kong, surrogacy is not against the law. However, using it for commercial surrogacy is prohibited. Surrogacy is gaining popularity in the West. However, it is still not widely accepted because of the strong sense of blood ties within the family in Chinese society. The non-commercialization and non-enforcement approaches of surrogacy are adopted in Hong Kong to protect the welfare of the child and the surrogate mother to uphold family values and family integrity, as well as to keep the commercial market out of family relationships.
\end{abstract}

Keywords: surrogacy, altruistic surrogacy, baby selling, commodity

\section{INTRODUCTION}

The word "surrogate" literally means "substitute" or "replacement" [1]. A surrogate mother is a woman who agrees to bear a child for another person or couple to the rear. The term genetic mother is who donates the ovum; gestational mother is who carries the pregnancy to term and delivers the child, and social mother is who rears the child [2]. The surrogate may not be the biological mother or just the gestational mother. The traditional surrogate is inseminated artificially with the sperm of a man.

\section{DOI: $10.5176 / 2345-7198 \_4.1 .117$}

(CThe Author(s) 2019. This article is published with open access by the GSTF
However, with the advanced reproductive technology, the gestational surrogate could become pregnant through in vitro fertilization.

A commercial surrogacy is a woman who agrees to bear the child for a fee over and above medical expenses. However, altruistic surrogacy is doing purely for a noncommercial purpose and aim for helping the infertile couple to have their child.

\section{CONTROVERSY OF SURROGACY}

In human history, the practice of surrogacy is not new things. The first statement of the term "surrogacy" is in the Holy Bible, the Old Testament (Genesis 16.1-15). The story is that because Sarai and Abraham could not conceive a child. Abraham "use" Sarai's maid, Hagar, as a surrogate mother, who give birth to Ishmael. In traditional Chinese culture, a common practice is a husband-concubine marriage, where a married man marries one or more women for the purpose of descendants [3]. Nowadays, it is unlawful to use concubine to be the surrogate after polygamy was abolished in Hong Kong in 1971 under the Marriage Reform Ordinance (CAP178) [4]

Some countries like Germany, France and Italy ban surrogacy. Some allow altruistic surrogacy only and prohibit the commercial surrogacy, like Australia Capital Territory and Hong Kong. Commercial surrogacy is practicing in countries like India from 2002 and some states in the US.

In 1986, there was a classic surrogate case (Baby M) in the US. William and Elizabeth Stern were worried about the health implications of pregnancy of Elizabeth's medical problem. Therefore, the Sterns signed a surrogate contract 
with a woman, named Mary Beth Whitehead, and paid her US10000 dollars to inseminate with William's sperm. After Mary Beth Whitehead had given birth to Baby M, her maternal instinct caused her to fight with the couple for its custody. Eventually, a New Jersey court found for the couple but awarded Mary Beth

Whitehead the right to visit the baby once a week. The case aroused controversy about moral issues in the US and the world.

A few years ago, in Hong Kong a tycoon who is single and has fathered a triplet of boys with the help of commercial surrogacy in California, USA. The incident has prompted a social debate on surrogacy and being a new hot topic in local media. Hong Kong is one of the regions having low birth rate could be associated with delayed marriage or choose to single in women. Surrogacy would be one of the options for women who have difficulties with conception and desperately wanting a child.

Today, even though surrogate motherhood is not an offence, there is no community-wide consensus for surrogacy in Hong Kong. According to Hong Kong Human Reproductive Technology Ordinance CAP561 [5] local registered medical practitioners can practice non-profitable surrogacy. The aim of this ordinance is to prevent custody litigation and controversy. The ordinance allows infertile couples to enjoy the bliss of parenting. In the meantime, this legislation also helps to protect both the surrogate mother and the child's welfare; respect the surrogate's right and autonomy.

Surrogacy is controversy because it risks the women's health, makes the womb as a commodity, constitutes babies-selling, changes the traditional family structure and values, degrades women productive dignity and exploits women from lower social stratum. The following paragraphs will elaborate more about the negative impacts of surrogacy for all parties involved.

\section{A. Treat women as commodity}

The physiological and psychological health of the surrogate mother ought to consider. Up to now, the long-term health outcomes, relational complexities and the social implications of surrogacy are not well known; it seems difficult to protect the health of the surrogate mother [6]. Therefore, lacking sufficient evidence to arouse the awareness of the harmfulness of the surrogacy for women consider entre the surrogacy contract.
Pregnancy has the risk, even though it is a natural process. A woman choosing to become pregnant and committed to raising her child is prepared to bear that risk. While, in commercial surrogacy, the concern is that the surrogate mother undertakes the same risk, but the motherhood goes to the commissioning couple. Death may become in the extreme case. The Daily Mail reported that a surrogate mother Natasha Caltabiano, aged 29, had died shortly after giving birth. She developed high blood pressure and a ruptured aorta after the delivery, dying 90 minutes later [7].

The mother of Ms. Caltabiano commented on the surrogate system, she said that surrogacy encouraged innocent women to risk their life for pregnancy. "Surrogacy caused Natasha's death," she said, "People must realize that childbirth isn't something you enter into lightly. It's still dangerous, but that is something surrogacy agencies don't go into". According to Surrogacy UK's rules, the commissioning couple had taken out a life insurance policy on Ms. Caltabiano, which is payable to her next of kin. According to newspaper reports, the commissioning couple, who already had five adult children between them from previous marriages, is now refusing to pay the bulk of the $£ 8,850$ promised as expenses payments to the surrogate. They said that they had sustained legal bills because of Ms. Caltabiano's death [7].

Commercial surrogacy separates pregnancy from parenting. In this way, the surrogate mother becomes a mere 'environment' or 'human incubator' for someone else's child [8]. The surrogate mothers use their wombs to bear children for other women and get payment. It is like rent out their wombs. However, pregnancy and childbirth are not only personal but also social behaviors. When a woman enters a surrogate contract, she is not restrict herself to follow procedures or to avoid doing something; it is using her womb to bear a fetus and give birth to a life. She will have a close relationship with the fetus throughout the whole process. In addition, the commissioning couple may withdraw from the surrogacy contract because of handicap child or refuse to adopt the newborn when the commissioning couple divorced.

Instead of expanding liberty and empowering women, commercial surrogacy permits the exploitation of economically disadvantaged women [9]. In the US, the price for the cost of hiring a gestational surrogate range between US\$50,000-120,000 including the medical and legal fees. This pay is more than the median income for a woman working retail sales or as nursing or home health aide [10]. The cost may imply surrogacy exploit low-income US women. In India, the income of the surrogates that the money they earned through surrogacy is equivalent to five years of total 
family income [11]. It is about US\$5000-6000 if they do bear the baby in a term. It seems surrogacy is an attractive source of income in India. Nevertheless, in fact, surrogacy is a stigmatized occupation in India. Almost all the surrogates would keep secret of their surrogacy from their communities, villages and even their relatives. They usually hid in the surrogate accommodation during the pregnancy [11]. If they have the alternatives, they will not do it because they do not want to be stigmatized. Surrogate women in India also want to be respected in the community. However, because of the "high payment", they have to trade off their dignity.

\section{B. Surrogacy and prostitution}

People opponent surrogacy like to metaphor commercial surrogacy as prostitution. Wamock (cited in [8]) described surrogacy as a form of exploitation similar to prostitution. Andrea Dworkin (cited in [8]), the well-known American feminist states that surrogate mother becomes a new branch of female prostitution with the help of advanced reproductive technology.... Women selling their reproductive capacities just like the prostitutes sold sexual service. The difference is surrogacy without the stigma of whoring. That is because there is no penile intrusion.

It is not difficult to find similarities between prostitution and commercial surrogacy. Physical service offer in both cases without a deeply personal or emotional relationship is required for the transaction to complete. In both cases, material compensation offer for the physical services provided.

\section{Baby selling}

Commercial surrogacy is also a form of baby selling. The commissioning couple pays money for the surrogate mother to bear the child. The surrogate mother gets the reward-money when she hands over the baby to the commissioning couple.

Pregnant women and her unborn baby have a bonding relationship, which is not equivalent to the relationship of the worker and his or her product. However, the commercial surrogacy makes the traditional pregnancy relationship commoditized. The surrogate mother has to deny the bonding and ownership of the child, and view herself as "human incubator", and the child as the "product". For instance, not like selling a property. Once sold, the previous owner will lose the property right. Although I could still harbor some sentimental feelings towards the property I sold, I have no claim to be recognized by others as having a relationship with it. However, because emotional ties are central to the parent-child relationship, they cannot be so easily ignored. Is selling house same as selling a baby? However, the new parental bond would not eliminate the existing bond.

In Baby M case, George J. Annas [12], an expert in health law studied the contract that was signed by the commissioning couple and the surrogate mother. Annas found that "Given this payment schedule- $\$ 1000$ for stillbirth, and $\$ 10,000$ to deliver a live child to the couple. There is no reasonable doubt that what is being paid for is a child, not an egg, gestation, and childbirth 'services' ". Baby M was a product being traded in this case. If there was any abnormality in this product, the surrogate mother only gets the one-tenth of payment. But the point is no matter the baby is a stillbirth, live birth or miscarriage, the surrogate mother has gone through the pregnancy, suffering from the miscarriage (if it does happen), or delivery a baby (no matter is live or not). Therefore, the surrogate mother should grand the full payment no matter what is the outcome of the pregnancy.

\section{Change the traditional family structure}

Surrogacy critic Andrew Kimbell says, here for the first time in the history of western law the idea that motherhood does not mean childbearing. A third person can help a woman to achieve it through commercial contract, which is both an ethical and legal free-fall.

New reproductive technologies (NRT) have created new forms of parenthood or, more specifically, non-genetic and social parenthood. Some of the worries raised out about NRT families in which only one parent has a genetic link to the child, or there is even no genetic link at all.

In commercial surrogacy, transferring parental rights create more parents (biological, surrogate and social mother). Again, I would like to use the Baby $\mathrm{M}$ case as an example. Baby $M$ has her biological mother Mary Beth Whitehead, social mother Elizabeth Stern and biological father, William Stern. In commercial surrogacy, if the gametes are not from the commissioning couple, the baby might have five persons involved in the surrogacy. Donated egg and sperm, so two unknown biological parents create the baby. The baby also has one surrogate mother and the social parents. There are some very extraordinary family forms in the society when commercial surrogacy introduces into the market in some countries. A gay couple and lesbian couple can have their kids with the help of commercial surrogacy. Single parent family created through commercial surrogacy. There is 
an increasing chance of incest because of all changing of the family structure.

\section{SURROGACY IN HONG KONG}

As mentioned before, surrogacy is not against the law in Hong Kong, but using it for commercial surrogacy is prohibited. Altruistic surrogacy is doing purely for a noncommercial purpose and aim for helping the infertile couple to have their biological child. For this reason, altruistic surrogacy is preferable in Hong Kong.

In Hong Kong the gestational mother is deemed to be the legal mother of the baby born through surrogacy; she has right over the baby as well as the right to the decision over the termination of pregnancy at any time. The commissioning couple can apply through adoption within three months of the birth of the child to become the legal parents of the child [9]. The surrogacy is not enforceable. Therefore, her right to motherhood and autonomy will be placed higher than the commissioning couple.

Although the surrogate mother is expected to take good care of her pregnancy and the obstetrician in charge of the surrogate mother should advise her to maintain a healthy lifestyle. Neither the commissioning couple nor anyone else has the right to control the surrogate mother as to her lifestyle during pregnancy, including nutrition, drinking habits, sexual behavior or the use of drugs. The commissioning couple cannot dictate the antenatal care received by the surrogate mother or force her to undergo either invasive or non-invasive prenatal procedures such as amniocentesis against her own will. The surrogate mother has the right to choose or refuse any medical treatment or procedure during pregnancy including termination of pregnancy (subject to the law governing the termination of pregnancy). By law, the surrogate mother is the mother of the baby. The commissioning couple will only become the legal parents of the baby upon the making of a parental order by the court under the Parent and Child Ordinance (Chapter 429) [13]. They must apply for this within six months of the birth of the baby. If the surrogate mother and her husband (if she is married) do not agree, the court will not make a parental order [14]. Because of the ethical concerns and the complexity involved in the arrangement, no case of surrogacy has been reported in Hong Kong so far.

\section{ETHICAL PRINCIPLES AND THEORY CONCERNING SURROGACY}

A. Autonomy
Liberal individualists support the surrogacy arrangement, and they argue that a woman has the right to do anything with her body as she chooses. In altruistic surrogacy, a woman enters the surrogacy because of her generosity to help the infertile couple, most of the time they are the family member of the commissioning couple or friend. She is doing it for love. She consciously knows the complications of the pregnancy and the implications of the surrogacy and is willing to bear the risk.

However, when the woman enters a commercial surrogacy contract, does she get the freedom to control the pregnancy? I do not think so because the surrogate mother cannot choose when to have the child, or how many children to bear. The surrogate mother's role is just a reproductive factory or slave. An even worse condition is if the child is abnormal, the decision of abortion or not control by the commissioning couple. In the situation, if the pregnancy is endangering the health of the surrogate mother. Does she has the autonomy to terminate the pregnancy?

Taking a surrogate mother in India as an example, who is living in poverty, with four or five children, elders to care for, and limited educational opportunities. They may be forced to do the surrogacy by her husband and in-law. The patrilineal marriage system in India may grant substantial influence to mother-in-laws in pressuring these women to undertake surrogacy arrangements [15]. That the woman in this situation, her autonomy is neglected.

\section{B. Beneficence}

From commissioning couple's point of view, it is no doubt that the infertile couples will benefit from the surrogacy because they can enjoy the procreation right with the help of surrogate mother, especially when the commissioning couples desperately want a child.

For the surrogate mothers, they could also benefit from the surrogacy, such as they could share the enjoyment of pregnancy, and redemption from giving up a child for adoption and previous abortions reported from the study [16].

\section{Nonmaleficence}

Nonmaleficence means not doing harm. Surrogacy is controversial. Given the fact that no surrogate arrangement is enforceable, there is not much room for the court to intervene in case of dispute. Hence, all parties are placed in a very vulnerable position. If the surrogate mother decides to keep the baby, the contracting parents 
will be hurt. If the commissioning parents do not to adopt the baby, the surrogate mother is left with all the responsibilities. If neither the commissioning parents nor the surrogate mother wants the baby, the child will be harmed.

Both the surrogate mother and the baby also have the risk of developing pregnancy complications throughout the surrogacy. The fetus in utero can be harmed by viral diseases of the gestational surrogate mother or by medications taken by the surrogate mother [2]. The surrogate mother has to bear the risk of developing the complications, like preEclampsia or thrombo-embolic events. These conditions can lead to life-threatening to the surrogate mother and fetus, which need for emergency terminating the pregnancy to save the surrogate mother's life. In worse condition, these may even cause the death of the surrogate mother, or to the development of chronic health problems [2]. What about if continue of the pregnancy will threaten the surrogate mother's health, while the baby is healthy during the pregnancy. Does the mother have the autonomy to termination of the pregnancy?

\section{Communitarian theory}

Communitarian ethics rejects the universality of individual rights for a more particularity focus on ethical problems, in which the good of the community is over the individual's right. This ethic bases on a recognition that individuals are "not selfsufficient alone ... outside a polis"'. Concerning the data presented above argument, this perspective would recognize the individual's right to know their genetic inheritance as potentially being sacrificed to the communal good of the family [17].

Communitarian priorities lie with the protection of social institutions such as the family and community as a means of enabling the individual, and ties individuals to a social duty to recognize that the communal good, in this case the protection of family cohesion, may contradict their interests or desires. From a communitarian perspective, the question to be asked is "what is most conducive to a good society, including the promotion of family values?"'

\section{DISCUSSION}

Assisted conception is designed to help involuntarily childless people to construct a family. In societies upholding a strong belief in intergenerational families, children play a crucial role in the extension and continuation of the family. Chinese have a strong sense of the continuity of the family tree. This feeling of belonging to the family is often revealed in a couple's decision-making before their seeking assisted conception. Biological and genetic connections highly emphasize within Chinese societies [14].

Of all forms of assisted conception, the use of a couple's gametes within a legal marriage accept in Chinese societies. This is because the child is still the genetically related to the married couple who can fulfill the obligation to the family. Meanwhile, the child can maintain the blood tie of the family, and his or her birth maintains the blood tie and the couple fulfil the obligations to the family. For those experiencing male infertility, assisted conception procedures such as sperm donation would be a solution, although using donated sperm is still not widely accepted. Couples need to overcome many cultural and social barriers to using sperm donation. Sperm donation is only used as a last resort [14].

Surrogacy is gaining popularity in the West. In Hong Kong, however, it is still not widely accepted because of the strong sense of blood ties within the family. Of all family relationships, the parent-child relationship is the most important. Surrogacy means requesting another woman to give birth to the child by carrying the embryo of the couple. The emotional connectedness between the surrogate mother and the infant is strong, although the infant has the blood of the genetic mother. However, surrogacy weakens the blood tie, and it somehow threatens the status of married wives within the family. Therefore, it is uncommon for infertile couples to choose this form of assisted conception [14].

With the help of the assisted reproductive technology, more and more infertile couples can become parents. Because surrogacy arrangements by definition involve more than two people, all of whom can legitimately claim that $\mathrm{s} / \mathrm{he}$ is the parent of the child. Parenthood is an inevitable problem in surrogate arrangements. Behind every praise of the success of the surrogacy, the danger always exists that a surrogacy arrangement would cause moral harm to the surrogate and the commissioning couple. On the other hand, surrogacy also changes the structure of traditional family structure. Even though Hong Kong is, a modernized city and the majority of the people still not accept surrogacy.

In Chinese culture, people who insist on the traditional notion that offspring is the continuation of the family line cannot accept the involvement of a third party in procreation [18]. Confucianism, one of the dominant philosophies in Chinese, it emphasizes on human relations rather than on individual rights as the basis of morality [19]. We regard surrogacy as immoral. 
That is because surrogacy will seriously jeopardize human relationship in Chinese society, even though surrogacy is an individual choice of the couple.

\section{CONCLUSION}

Procreation is one of the rights of human beings. With the advanced reproductive technology, more and more couples can have their biological children despite the difficulty in conception. Since the incident of Baby M case in 1986, surrogacy becomes a popular option for couples fail in procreation. However, surrogacy remains a controversial issue, especially when it involves payment. In commercial surrogacy, children become commodities as products for profit rather than cherishing them as persons worthy of love and care. Commercial surrogacy also degrades women by treating their bodies as factories and by paying them not to bond with the children they bear. It also changes the traditional family structure and values, and degrades women productive dignity and exploits women from lower social stratum.

In Hong Kong, commercial surrogacy is illegal, and the surrogacy is restricted to married couples only. The non-commercialization and non-enforcement approaches are adopted to protect the welfare of the child and the surrogate mother to uphold family values and family integrity, as well as to keep the commercial market out of family relationships.

Even though altruistic surrogacy is allowed in Hong Kong, it should not promote because the majority of the people in Hong Kong does not accept surrogacy. In the meantime, all parties' rights and autonomy should be considerate in the process of the altruistic surrogacy in Hong Kong. http://www.dailymail.co.uk/news/article335871/Surrogate-mum-dies-giving-birth.html

8. van Niekerk, A. \& van Zyl, L. (1995). The ethics of surrogacy: women's reproductive labour. Journal of Medical Ethics, 21: 345-349.

9. Tao, J. P. (1997). Assisted reproductive technology: the case of surrogacy. In Becker G. K.(Ed.) Reproductive technology and ethics: procreative liberty and its limits. CAE Occational Paper Series Number 97003

10. Twine, F. W. (2011). Outsourcing the womb: race, class, and gestational surrogacy in a global market. New York: Routledge Taylor \& Francis Group.

11. Pande, A. (2010).Commercial surrogacy in India: manufacturing a perfect mother-worker. Signs, 35, 969-992.

12. Annas, G. J. (1987). Baby M: babies (and justice) for sale. Hasting Center Report, 17, 14

13. Hong Kong Parent and Child Ordinance Chapter 429 (1993) https://www.elegislation.gov.hk/hk/cap429

14. Ng, E., Liu, A., Chan, C. \& C. Chan, (2004). Hong Kong A Social, Legal and Clinical Overview. In Blyth, Eric, Landau, Ruth.; Third Party Assisted Conception Across Cultures : Social, Legal, and Ethical Perspectives. New York: Jessica Kingsley Publishers.

15. Standford University (2008). Surrogate motherhood in India understanding and evaluating the effects of gestational surrogacy in women's health and rights. Retrieved:

http://www.stanford.edu/group/womenscourage/Surr ogacy/moralethical.html

16. Ciccarelli, J.C., Beckman L. J. (2005). Navigating rough waters: an overview of psychological aspects of surrogacy. Journal of Social Issues, 61, 30-31.

17. Burr, J \& Reynolds, P. (2008). Thinking ethically about genetic inheritance: Liberal rights, communitarianism and the right to privacy for parents of donor insemination children. Journal of Medical Ethics, 34, 281-284.

18. Liao, J. Dessein, B. \& Pennings, G. (2010). The ethical debate on donor insemination in China. Reproductive Biomedicine Online, 20, 895-902.

19. Tao, J. P. (2000). Two perspectives of care: Confucian Ren and feminist care. Journal of Chinese Philosophy, 27, 215-306

\section{REFERENCES}

1. Oxford dictionaries (2012). Retrieved: http://oxforddictionaries.com/

2. Ber, R. (2000). Ethical issues in gestational surrogacy. Theoretical Medicine and Bioethics, 21, 153-169.

3. Saso, M. (1999). Velvert Bond: The Chinese Family. Carmel: New Life Center.

4. Hong Kong Ordinances CAP178 (1970). Retrieved: https://www.elegislation.gov.hk/hk/cap178

5. Hong Kong Ordinances CAP 561 (2000). Retrieved: https://www.elegislation.gov.hk/hk/cap561

6. Tieu, M. M. (2009). Altruistic surrogacy: the necessary objectification of surrogate mothers. Journal of Medical Ethics, 35, 171-175.

7. Anon.(2005). Surrogate mum dies after giving birth Daily Mail 29 January 2005. Retrived: 